\title{
MODELLING SPATIO-TEMPORAL CHANGES OF TROPICAL FOREST GOVER IN THE NORTH-EASTERN REGION OF BANGLADESH: CONTEXT OF TRADITIONAL AND CO-MANAGEMENT PARADIGMS
}

\author{
Ahmed N¹, Mahbub RB ${ }^{2}$, Hossain $\mathbf{M M}^{3}$ \& Sujauddin $\mathbf{M}^{2, *}$ \\ ${ }^{1}$ Department of Electrical and Computer Engineering, School of Engineering and Physical Sciences, North South University, \\ Bashundhara, Dhaka-1229, Bangladesh \\ ${ }^{2}$ Department of Environmental Science and Management, School of Health and Life Sciences, North South University, \\ Bashundhara, Dhaka-1229, Bangladesh \\ ${ }^{3}$ Institute of Forestry and Environmental Sciences, University of Chittagong, Chittagong 4331, Bangladesh
}

*mohammad.sujauddin@northsouth.edu

Submitted February 2019; accepted July 2019

\begin{abstract}
Forests in Bangladesh are losing their land footprint mainly due to anthropogenic onslaught. Not much is known about the changes in tropical forest cover in Sylhet Forest Division (SFD) of Bangladesh in the backdrop of mixed managerial paradigms (i.e. traditionally managed and co-managed). This study was aimed at (1) modelling changes in forest cover over the temporal domain 1988-2018, (2) projecting future gain/loss of forest cover, and (3) comparing changes between areas under co-management and traditional management. The study was based on satellite image pixel classification through machine learning, area interpolation, regression-based modelling for forest cover and future projections. SFD, comprising 18 forests, has been grouped into 10 forest patches for analysis. Mean forest cover area was 121,533 ha in 1988-1997, which declined to 120,216 ha in 1998-2007. Comparison between the area values of the two time intervals showed that the forest cover area has increased from 120,216 ha in 1998-2007 to 124,556 ha in 2007-2018. In the managerial perspective, the study showed aggregated loss in patches under co-management and aggregated gain in patches under traditional forest management. This study has legislative implications from managerial perspective of forest cover changes.
\end{abstract}

Keywords: Forest cover modelling, Sylhet Forest Division, forest co-management, Classification and Regression Trees

\section{INTRODUCTION}

Tropical forests, mainly located in countries with high population densities and growing economies, are declining at a dramatic rate of about $2101 \mathrm{~km}^{2}$ year-1 (Hansen et al. 2013). While reviewing deforestation across the globe, the managerial perspectives of forests need to be considered, since anthropogenic interventions in the form of forest management are the drivers of deforestation and linked to $26 \%$ of all forest area losses (Curtis et al. 2018). Unfortunately, forest cover losses across all forest types in the world have become inexorable in the $20^{\text {th }}$ and $21^{\text {st }}$ century (Lamb et al. 2005) and Bangladesh is no exception (Mahbub et al. 2019). Studies contextualising forest cover changes with managerial paradigms in Bangladesh are lacking and this research aims at filling that void.

The forest cover in Bangladesh has declined from $2,314,000$ to $1,408,600$ ha between 1930 and 2014 (Reddy at al. 2016). The Forest Management Wing of the Forest Department in Bangladesh classifies forests of the country into five administrative circles, viz. coastal circle (southern coast), central circle (center and north-eastern region), Chittagong circle (south-eastern region), Rangamati circle (hilly area of south-eastern region) and Khulna circle (south-western region). The forest patches of Sylhet Forest Division (SFD) fall within the northeastern region of the country under the central 
forest circle. Forests in SFD possess unique forest physiognomy as they harbour different ecological forest types including tropical wet evergreen and semi-evergreen forests with fresh water swamp forests (Haque 2013). Unfortunately, the forests and biodiversity therein are under anthropogenic threats triggered by unplanned development activities and inappropriate governance interventions.

Taxpayers' money and foreign aids are invested every year for the management of forests in Bangladesh. However, irrespective of forest management approaches, lack of information on the real changes of forest cover in this region is evident from the absence of relevant scientific literature. Apart from the traditional forest management by the forest department, recently a new forest management paradigm branded as co-management has been introduced into different forest areas in Bangladesh including the SFD. However, the overall status of forests under different management paradigms is yet to be compared objectively.

SFD comprises 18 individual forests which have been studied sporadically in terms of forest cover modelling with some forests receiving greater academic interests (e.g. Halim et al. 2008, Redowan et al. 2014, Islam et al. 2019) compared with the rest. There has been no study done to summarise the aggregated trend of forest cover changes in this region. Studies on individual forests adopted non-standardised and incomparable approaches inhibiting direct comparison and further necessitating a comprehensive study of forest cover changes in SFD. The evolution of machine learning algorithms to conduct GIS-based assessment of satellite imagery to study forest cover changes has offered the unique opportunity to conduct such an investigation. In this backdrop, this study evaluated forest cover changes in the context of competing forest management paradigms in this region. Comparison between forest areas under different management paradigms is crucial to choose among alternatives for best outcome. Accordingly, this study modelled the trend of forest cover changes through satellite image analysis by using machine learning algorithms within the temporal domain of 1988-2018 to generate future projections of forest cover in SFD and compared forest co-management with traditional forest management.

\section{MATERIALS AND METHODS}

\section{Study area}

The 18 forests in this study are under the SFD lying between $23^{\circ} 55^{\prime}-25^{\circ} 12^{\prime} \mathrm{N}$ and $90^{\circ} 55^{\prime}-92^{\circ}$ $30^{\prime} \mathrm{E}$. The physical geography of the study area is characterised by terrains including flat land, elevated land, reed land and fresh water swamps. The majority of tea estates in the country are grown at the fringes of forest patches (Rahman et al. 2010). SFD spreads over four administrative districts, viz. Sylhet, Moulvibazar, Habiganj and Sunamganj.

\section{Selection of forest patches for analysis}

The forests included in the study were categorised under 10 forest patches (regions of interest) for analysis following Biswas and Choudhury (2007) and Rana 2011 (Table 1). Among these 18 forests, some were overlapping and inseparable; hence, they were grouped under the same patch. Rectangular quadrilaterals were created around the study areas. Shapefiles were kept small enough to not include other forests and big enough to not exclude forest patches. The international border of Bangladesh was used to exclude forest patches within the geographic scope of India. The region within the intersection between rectangular shapefiles and international boundary of Bangladesh gave the final study areas shown in Figure 1.

\section{Analytical scheme}

The analytical scheme of the study is shown in Figure 2. Data on past measurements of forest cover area were extracted from available literature on SFD forests and preprocessed. All forest patches within SFD were identified and located based on the literature. In addition, satellite imagery of forest patches in the area were also utilised for the selection of study area to ensure inclusion of patches under forest cover within the study area polygons while excluding non-forest vegetation, i.e. tea estates. Forest areas under co-management and traditional management were demarcated into polygons for comparison based on information from literature. The satellite images were then used to train the machine learning algorithm 
Table 1 Studied forest patches in Sylhet Forest Division, Bangladesh

\begin{tabular}{ll}
\hline Forest Patch & Forest \\
\hline Remakalenga & Tarap Hill Reserved Forest \\
& Dinarpur Hill Reserved Forest \\
& Satgao Dinarpur Hill Reserved Forest \\
& Dinarpur Hill Reserve \\
& Modhupur Reserved Forest \\
& Modhupur Hill Reserved Forest \\
& Barshijhora Forest \\
Lawachara & West Bhanugach Reserved Forest \\
& Patharia Hill Reserved Forest \\
Madhabkunda & Rajkandi Hill Reserved Forest \\
Rajkandi & Harargaj Reserved Forest \\
Muraichara & Tilagor Reserved Forest \\
Khadimanagar & Khadimnagar Reserved Forest \\
Ratargul & Ratargul Swamp Forest \\
Bhatera & Bhatera Forest Reserve \\
Mayaban & Mayaban Swamp Forest \\
Satchori & Roghunandan Hill Reserved Forest \\
& Uchail Reserved Forest \\
\hline
\end{tabular}

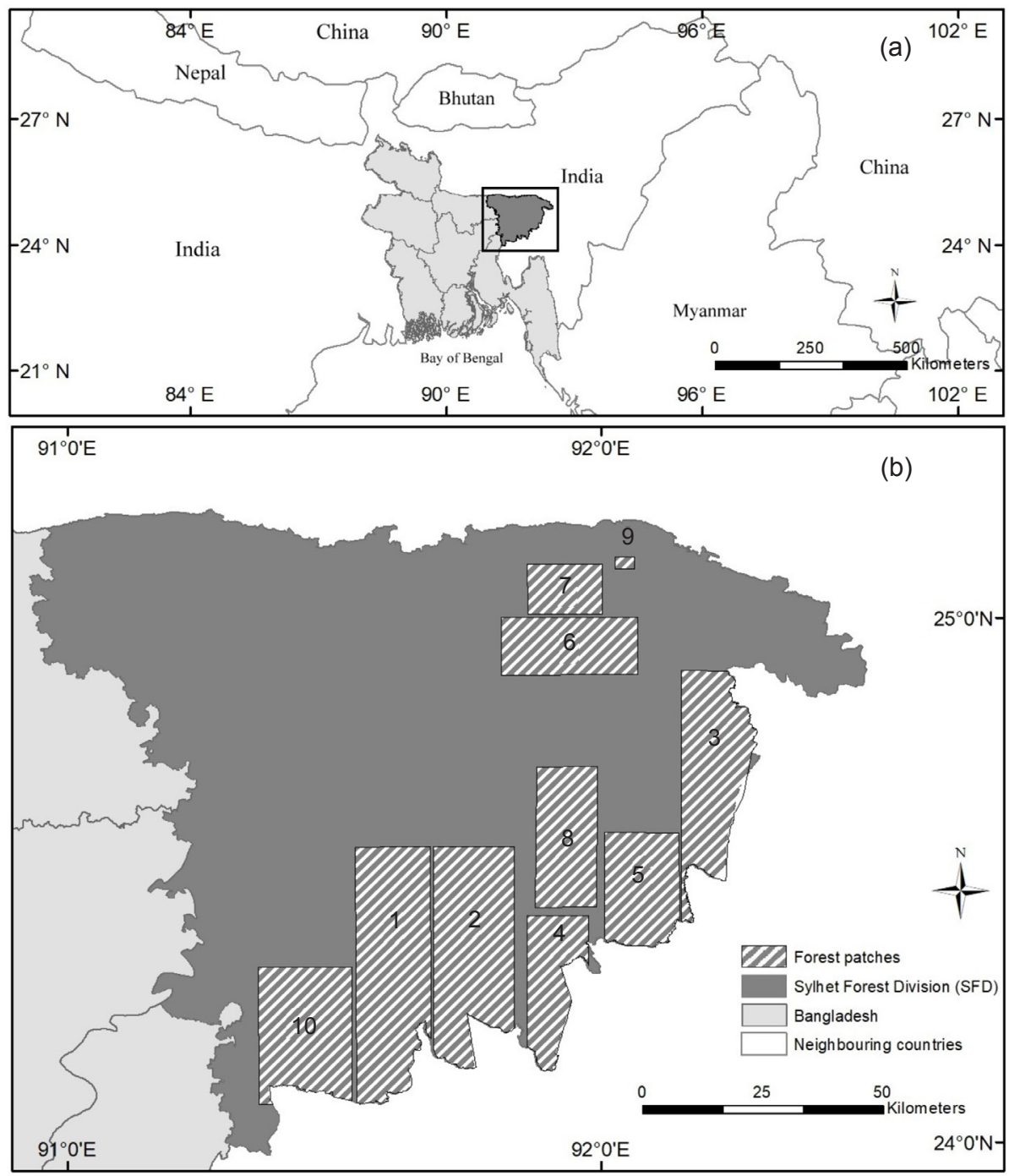

Figure 1 Study area: (a) map of Bangladesh highlighting Sylhet division and (b) shapefiles of 10 forest patches of Sylhet Forest Division (1: Remakalenga, 2: Lawachara, 3: Madhabkunda, 4: Rajkandi, 5 : Muraichara, 6: Khadimnagar, 7: Ratargul, 8: Bhatera, 9: Mayaban, 10: Satchori) 


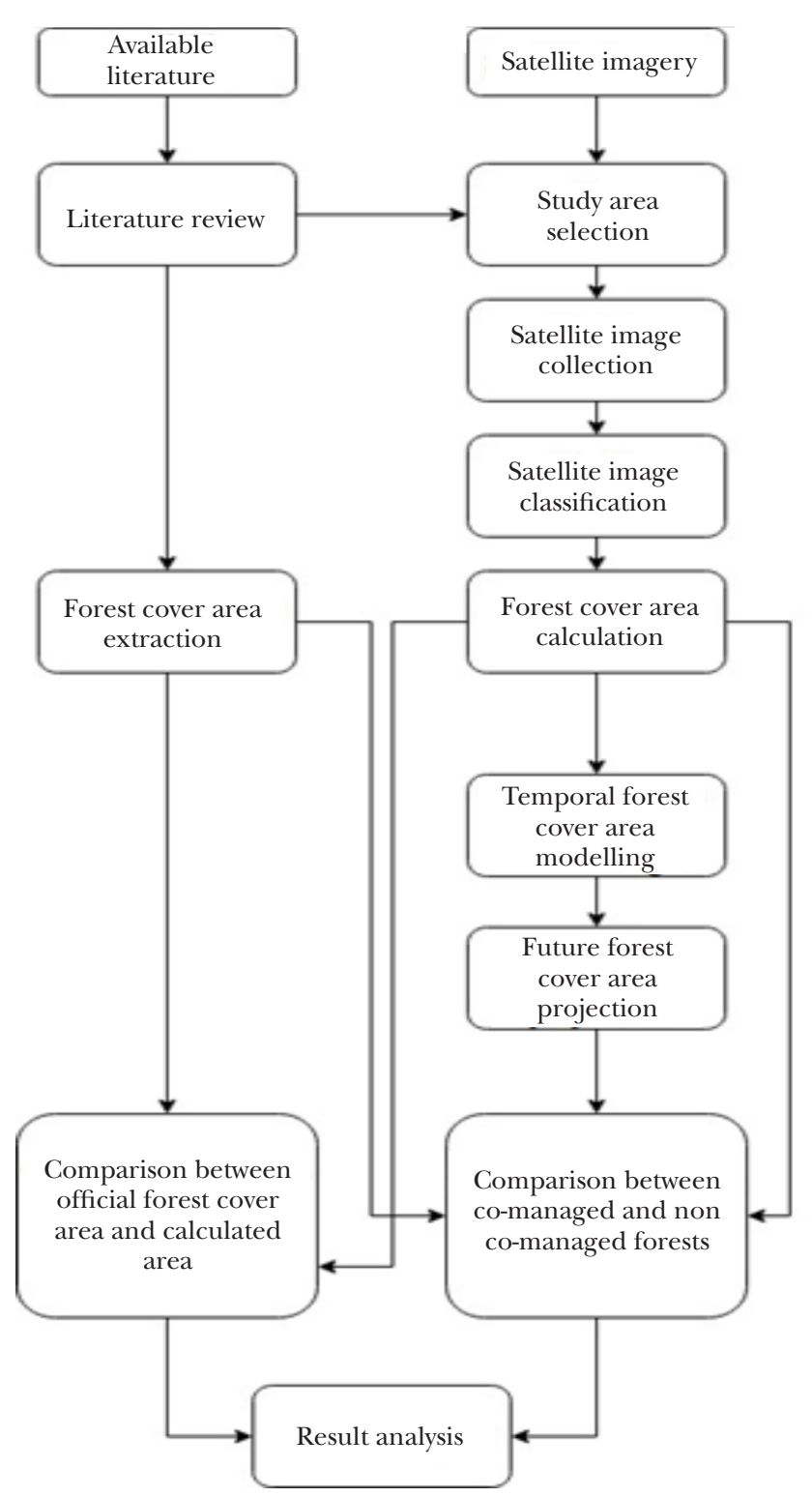

Figure 2 Process flow of the study

for landuse classification. The trained model was then applied to classify the entire study area into forest and non-forest regions and their respective areas were calculated. Time series datasets were obtained for modelling of temporal forest cover area by applying the classification model on satellite images of different years. Future projection was made to evaluate the fate of forest patches based on time series models. The datasets were used to compare trends of forest cover changes between forest patches under co-management and traditional management. Inferences were made based on the datasets and comparisons to suggest policy recommendations.

\section{Data}

Spatio-temporal changes in forest cover within SFD were investigated by utilising two sets of data. The first, data on forest cover from existing literature (Global Forest Watch 2014, Bangladesh Forest Department 2016) and, second, data from the analysis of satellite imagery from Landsat-5 and Landsat- 8 2018, obtained from the US Geological Survey. Comparison was made between the two sets of data to evaluate anomalies. The entire study area was covered by satellite image scenes of Landsat path 136 and row 43. Absence of cloud cover in the satellite images was ensured. Satellite images of the study area were collected for the temporal window 1988-2018. Due to cloud cover over the study areas and low image quality, images for 1993, 2002 and 2012 were discarded which gave a total of 28 Landsat scenes for satellite image analysis.

\section{Satellite image classification}

\section{Land cover classes}

Individual pixels were divided into two classes, namely, forest and non-forest. Forest class included pixels falling into the main forest patch, whereas urban area, open area (cultivated and uncultivated), water bodies (wetlands and rivers), etc. were categorised as non-forest class.

\section{Algorithm}

The Classification and Regression Tree (CART) (Breiman et al. 2017) predictive model was used for the analysis. CART has been utilised for similar purposes in recent times (Ahmed et al. 2019). Since assignment of pixels to disjoint classes translates into the target variable taking discrete values, the model is more specifically addressed as a classification tree which is a specialised form of decision trees. Pixels were manually classified based on visual photointerpretation as training data.

\section{Time series modelling of forest cover area}

\section{Variability}

Calculated area values from satellite images vary depending on the time and year of image 
capture, image quality, cloud cover, etc. Due to relatively slow process of forest growth, changes in forest cover became more discernible when compared between 5- and 10-year intervals. However, annual area calculation captured the continuous trend and provided more reliable inferential decisions if converted into suitable statistical summaries after adjustment for noise. Hence, this study considered continuous time series area data.

\section{Area calculation}

The classification algorithm outputs a raster image, with binary values of 0 and 1 for pixels classified respectively as forest and non-forest. In equation $1, \mathrm{~m}$ is the spatial resolution (in $\mathrm{m}$ ) of the output raster image, $\mathrm{n}_{\mathrm{i}}$ is the number of pixels of class $i$ (where $i$ takes values 0 and 1 for this case) in the output raster, and $A_{i}$ is the physical area $\left(\mathrm{in}^{2}\right.$ ) covered by the pixels in the $\mathrm{i}^{\mathrm{t}^{\text {th }}}$ class. Thus, for class forest where $\mathrm{i}$ equals $0, \mathrm{n}_{0}$ represents the number of pixels of the class forest and $\mathrm{A}_{0}$ represents the forest cover area.

$$
\mathrm{A}_{\mathrm{i}}=\mathrm{n}_{\mathrm{i}} \times \mathrm{m}^{2}
$$

\section{Interpolation}

Satellite images for 1993, 2002 and 2012 were not suitable for classification due to direct cloud cover over the study area and low image qualities. Missing area values for those three years were generated via linear interpolation (De Boor 1978). Considering $A_{t}$ (unknown value) is the area of a forest in year $t, A_{t-1}$ is the area value for year $t-1$ and $A_{t+1}$ is the area value for year $t+1$, linear interpolation was individually applied on each of the 10 forest patches based on equation 2 .

$$
A_{t}=\frac{(t-(t-1)) \times\left(A_{t+1}-A_{t-1}\right)}{((t+1)-(t-1))}+A_{t-1}
$$

\section{Ordinary least squares regression model}

Ordinary least squares (OLS) regression (Kenney \& Keeping 1962) model was used for future projection through a univariate linear regression model. Since single predictor variable was used and weights were obtained from normal equations, normalisation of features was not necessary. The hypothesis function $h_{\theta}(x)$ in equation 3 is dependent on two parameters/ weights, i.e. the bias term $\theta_{0}$ and gradient term $\theta_{1}$. The unit for $\theta_{0}$ is ha and the unit for $\theta_{1}$ is ha year ${ }^{-1}$.

$$
\mathrm{h}_{\theta}(\mathrm{x})=\theta_{0}+\theta_{1} \mathrm{x}
$$

In the equation, $\mathrm{x}$ represents input as years and $h_{\theta}(x)$ represents predicted area values. The solution of the equation (which involves finding the values of $\theta_{0}$ and $\theta_{1}$ ) was calculated using equation 4 , where $\mathrm{X}$ is the feature matrix, $\mathrm{Y}$ is the vector of target values and $\theta$ is the weight vector. A total of 10 separate OLS regression models were trained and tested for each of the 10 forest patches.

$$
\theta=\left(\mathrm{X}^{\prime} \mathrm{X}\right)^{-1} \mathrm{X}^{\prime} \mathrm{Y}
$$

\section{Model testing and error analysis}

The total dataset contained calculated areas of forest cover for the 10 forest patches for the time span of 31 years (1988-2018). Thus, there were 31 forest cover area values for each of the 10 forest patches. The forest cover area data was then randomly split into training data $(80 \%)$ and testing (20\%) data.

The testing data predictor variable (time in years) was used to generate values predicted by the OLS regression model. The predicted values were compared with the testing target variable (forest cover area) to assess the reliability of prediction by the model for each of the forest patches. Mean squared error (MSE) metric was calculated to estimate the error of the model.

Trained models were used to predict future forest cover areas for each of 10 patches for the years 2025, 2050, 2075 and 2100. Besides comparing future projections of individual forest patch, differences in future forest cover projections between traditional management and co-management were also explored for insight into the consequences of management paradigms.

ArcGIS was used for creating the map of study area. Satellite image collection, geoprocessing and classification were performed on Google Earth Engine (Gorelick et al. 2017) via JavaScript API. Modelling and predictions were performed via Python's scikit-learn library (version 0.19.0). Plotting and visualisations were produced via ggplot2 (version 2.2.1) package of $\mathrm{R}$ language. 


\section{RESULTS AND DISCUSSION}

\section{Spatio-temporal forest cover changes}

The CART classifier was used to determine the landuse and land cover class of each pixel in the satellite images of the study area. Figure 3 shows the results of the classification for all the 10 forest patches of SFD at 10-year intervals within the temporal domain 1988-2018.

The temporal domain of the study was grouped into three intervals, viz. (1) 1988-1997, (2) 1998-2007 and (3) 2008-2018. Means and standard deviations of areas under forest cover for each of the 10 patches as well as the entire SFD were derived for the intervals (Table 2). The total forest cover area of SFD showed a declining trend between intervals 1988-1997 and 1998-2007 which subsequently increased between 1998-2007 and 2008-2018. The mean forest cover area of SFD throughout the entire temporal domain of the study (1988-2018) can be considered a suitable baseline. Compared with the mean value for the entire temporal window, intervals 1988-1997 and 1998-2007 showed lower forest cover and interval 2008-2018 showed higher forest cover area value.

\section{Validation of data}

Calculated area values of SFD obtained in the study was validated using data from literature (Global Forest Watch 2014, Bangladesh Forest Department 2016) (Figure 4). Due to unavailability of continuous data in the literature, only area values for 2001, 2010 and 2016 were considered for comparison. Area values for 2001 and 2010 were compared with values from Global Forest Watch and area value for 2016 was compared with data from Bangladesh Forest Department. The calculated areas in this study were similar to Global Forest Watch but differed significantly with data from Bangladesh Forest Department for 2016. For 2001 and 2010, the differences between Global Forest Watch and this study were only 11,776 (10\%) and 15,651 ha $(12 \%)$ respectively. In contrast, a substantial difference of 61,270 ha $(53 \%)$ in area values was observed compared with records from Bangladesh Forest Department. The difference could be attributed to the method of area estimation whereby Bangladesh Forest Department estimated areas using error-prone manual field data collection while this study and Global Forest Watch used satellite image analysis.

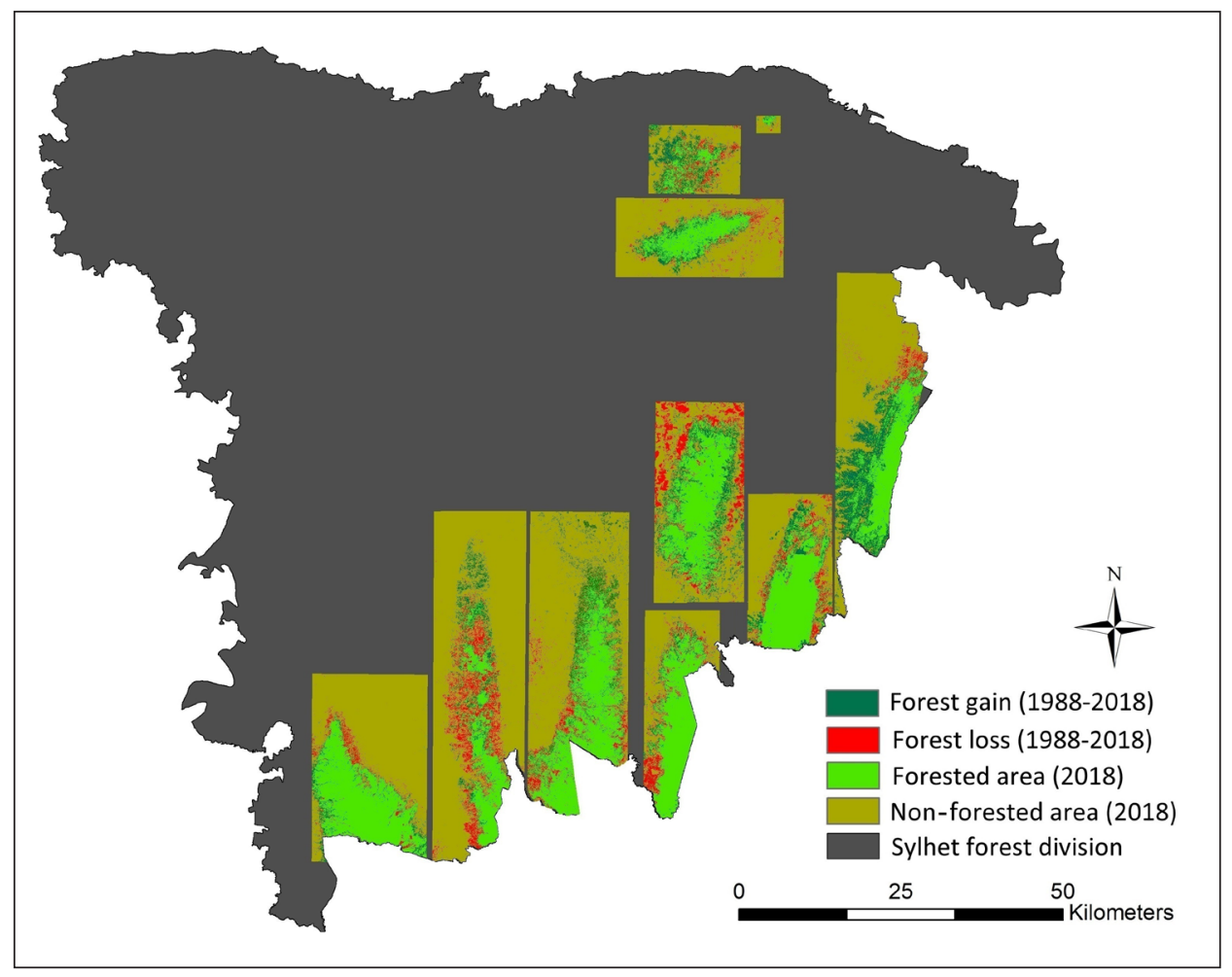

Figure 3 Spatio-temporal distribution of forest cover gain and loss in Sylhet Forest Division, Bangladesh from 1988 to 2018 
Table 2 Temporal forest cover area (ha) comparison of all forest patches of Sylhet Forest Division (SFD)

\begin{tabular}{|c|c|c|c|c|c|c|c|c|}
\hline \multirow[t]{2}{*}{ Forest patch } & \multicolumn{2}{|c|}{ 1988-1997 } & \multicolumn{2}{|c|}{ 1998-2007 } & \multicolumn{2}{|c|}{ 2007-2018 } & \multicolumn{2}{|c|}{ 1988-2018 } \\
\hline & Mean & SD & Mean & SD & Mean & SD & Mean & SD \\
\hline Remakalenga & 14602 & 1758 & 13050 & 1736 & 12632 & 2101 & 13402 & 2010 \\
\hline Lawachara & 23047 & 1399 & 22838 & 1674 & 23156 & 807 & 23018 & 1290 \\
\hline Madhabkunda & 11945 & 1123 & 11366 & 971 & 13920 & 2492 & 12459 & 2000 \\
\hline Rajkandi & 13796 & 691 & 14031 & 548 & 13543 & 1474 & 13782 & 1000 \\
\hline Muraichara & 15275 & 603 & 16006 & 748 & 15319 & 1247 & 15526 & 953 \\
\hline Khadimnagar & 7614 & 458 & 7199 & 603 & 7249 & 345 & 7351 & 496 \\
\hline Ratargul & 3405 & 374 & 3831 & 498 & 3386 & 972 & 3536 & 689 \\
\hline Bhatera & 15792 & 3041 & 15972 & 1543 & 19205 & 1929 & 17061 & 2710 \\
\hline Mayaban & 189 & 36 & 190 & 51 & 185 & 41 & 188 & 42 \\
\hline Satchori & 15863 & 1329 & 15730 & 915 & 15956 & 1111 & 15853 & 1096 \\
\hline Total SFD & 121,533 & 5139 & 120,216 & 3902 & 124,556 & 6099 & 122,181 & 5328 \\
\hline
\end{tabular}

$\mathrm{SD}=$ standard deviation

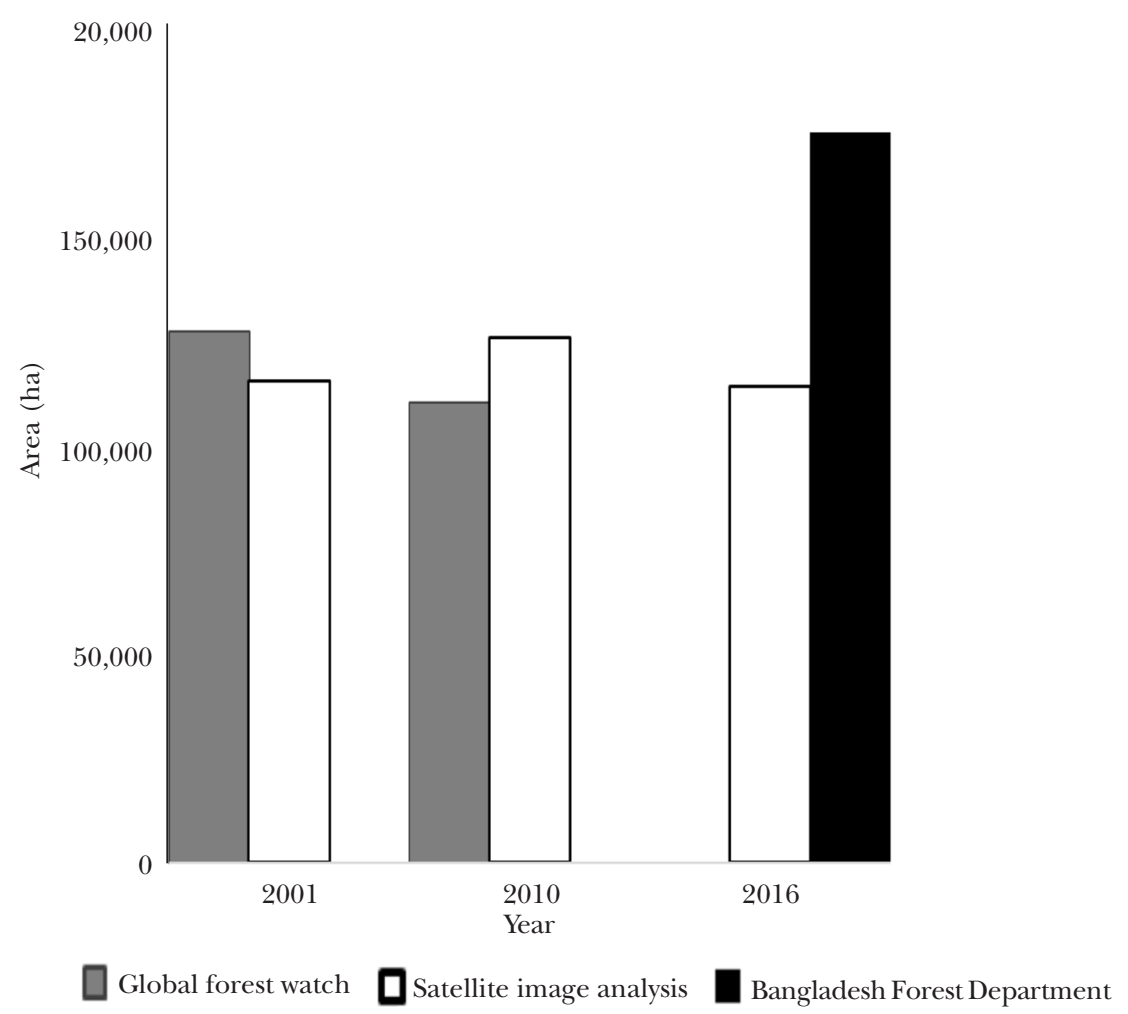

Figure 4 Comparison of derived forest cover area in Sylhet Forest Division with the area recorded by Bangladesh Forest Department (2016) and Global Forest Watch (2014)

\section{Future projection of forest cover changes}

The future projection of changes in forest cover at the forest patches in SFD was obtained from the coefficient term of the respective OLS regression models (Table 3 ). Positive values indicated growing forest patches and negative values, forest cover loss in the patches. Magnitude of the coefficient term determined the rate of growth or loss. The magnitude of the bias terms of OLS regression models defined the total mean forest cover area throughout the temporal domain of the study. The coefficient of determination $\left(\mathrm{r}^{2}\right)$ for all regression models 
indicated excellent fit of the model to the area values calculated from satellite image analysis (Table 3). The best-fit lines of regression models are shown in Figure 5. However, factors other than temporal domain also affected forest cover area which were not included in this study due to limitations of reliability and unavailability of data.

\section{Testing and error analysis}

A comparison between mean forest cover areas in Table 2 and MSE in Table 3 revealed size dependency of error in the regression model. MSEs increased with increasing sizes of forest patches, i.e. with increasing numbers of pixels. The contribution of noise in the testing data and the randomness in splitting the datasets for testing contributed marginally to MSEs compared with forest patch sizes. However, due to smaller sizes of forest patches in SFD, the models developed and estimates thereof were considered reliable.

\section{Future projection}

Due to the use of OLS regression model, continued trend of change was obtained from future projections of forest cover for all the patches in SFD. The projection indicated future increase in patch sizes for four forest patches (Bhatera, Lawachara, Madhabkunda and Ratargul) and decreasing areas for the remaining six (Khadimnagar, Mayaban, Muraichara, Rajkandi, Remakalenga and Satchori). This mixed outcome may be attributed to the differences in the rate of interferences, management paradigm and recent conservation and plantation activities.

\section{Traditionally managed vs co-managed forest patches}

Forest cover changes in SFD was evaluated from the perspective of forest management through comparison between forest patches under co-management and those under traditional management. Co-management was introduced in Bangladesh in 2004 as a productive and protective forestry management approach (Bangladesh Forest Department 2017). The results indicated a continuous increasing trend of aggregated forest cover areas in forest patches under traditional management and a decreasing trend in the aggregated forest cover area in forest patches under co-management (Figure 6). We need to use this result as a short-term evaluation of the performance of co-management paradigm. Only continued evaluation will be able to judge whether co-management is effective or not. Due to the longer growth cycles of forests, it would be unreasonable to mark co-management as ineffective.

Table 3 Future projections (2025, 2050, 2075 and 2100) of forest cover area (FCA) of all forest patches of Sylhet Forest Division (SFD) evaluated on coefficient of determination $\left(r^{2}\right)$ and mean squared error (MSE)

\begin{tabular}{|c|c|c|c|c|c|c|c|}
\hline \multirow[t]{2}{*}{ Forest patch } & \multirow{2}{*}{$\begin{array}{c}\text { Model } \\
\text { equation }\end{array}$} & \multirow[t]{2}{*}{$\mathrm{r}^{2}$} & \multirow[t]{2}{*}{ MSE } & \multicolumn{4}{|c|}{ Future projections (ha) } \\
\hline & & & & 2025 & 2050 & 2075 & 2100 \\
\hline Remakalenga & $\begin{array}{l}\mathrm{FCA}=(-113.62 \times \text { Year })+ \\
240,987.86\end{array}$ & 0.978 & 5149,040 & 10,903 & 8062 & 5222 & 2381 \\
\hline Lawachara & $\mathrm{FCA}=(11.16 \times$ Year $)+665.13$ & 0.997 & $1,039,491$ & 23,264 & 23,543 & 23,822 & 24,101 \\
\hline Madhabkunda & $\mathrm{FCA}=(93.54 \times$ Year $)-174,194$ & 0.976 & 883,3379 & 14,517 & 16,856 & 19,195 & 21,533 \\
\hline Rajkandi & $\begin{array}{l}\mathrm{FCA}=(-18.51 \times \text { Year })- \\
50,861.37\end{array}$ & 0.995 & 701,494 & 13,375 & 12,912 & 12,449 & 11,986 \\
\hline Muraichara & $\begin{array}{l}\mathrm{FCA}=(-15.52 \times \text { Year })+ \\
46,629.45\end{array}$ & 0.996 & 106,5584 & 15,185 & 14,797 & 14,408 & 14,020 \\
\hline Khadimnagar & $\mathrm{FCA}=(-11.2 \times$ Year $)+29,802.89$ & 0.995 & 89,467 & 7104 & 6824 & 6544 & 6263 \\
\hline Ratargul & $\mathrm{FCA}=(4.6 \times$ Year $)-5678.38$ & 0.965 & 601,619 & 3,637 & 3,752 & 3,867 & 3,982 \\
\hline Bhatera & $\begin{array}{l}\text { FCA }=(158.64 \times \text { Year })- \\
30,0696.31\end{array}$ & 0.977 & $3,755,715$ & 20,551 & 24,517 & 28,483 & 32,449 \\
\hline Mayaban & $\mathrm{FCA}=(-0.14 \times$ Year $)+477.45$ & 0.954 & 3070 & 185 & 181 & 177 & 174 \\
\hline Satchori & $\begin{array}{l}\mathrm{FCA}=(-4.91 \times \text { Year })- \\
25,699.78 .31\end{array}$ & 0.995 & $1,522,349$ & 15,745 & 15,622 & 15,499 & 15,376 \\
\hline Total SFD & $\begin{array}{l}\text { FCA }=(104.02 \times \text { Year })- \\
86,164.89\end{array}$ & 0.998 & $50,949,178$ & 124,469 & 127,069 & 129,670 & 132,270 \\
\hline
\end{tabular}




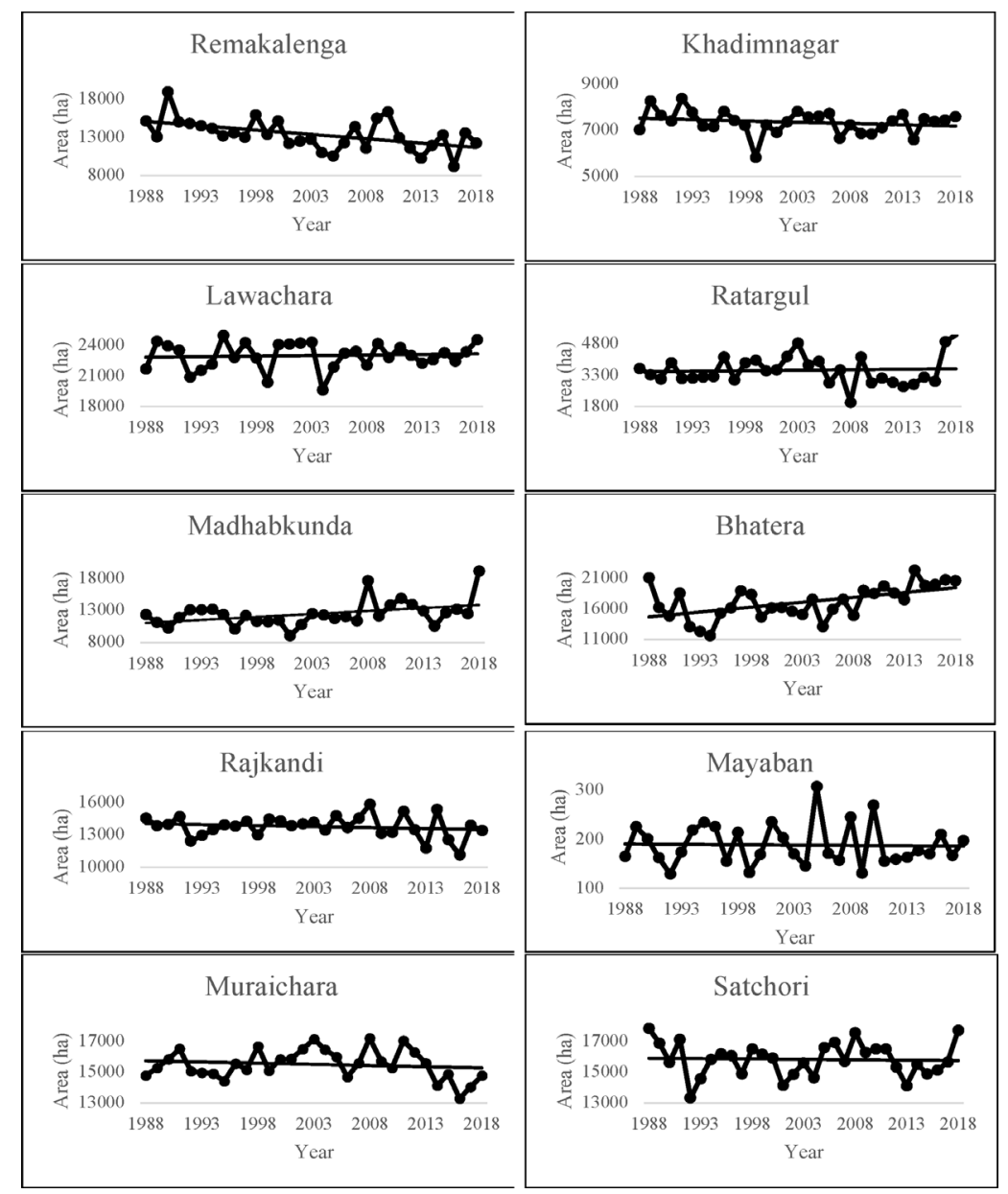

Figure 5 Yearly forest cover area and ordinary least squares regression models (shown as straight lines) of all forest patches in Sylhet Forest Division

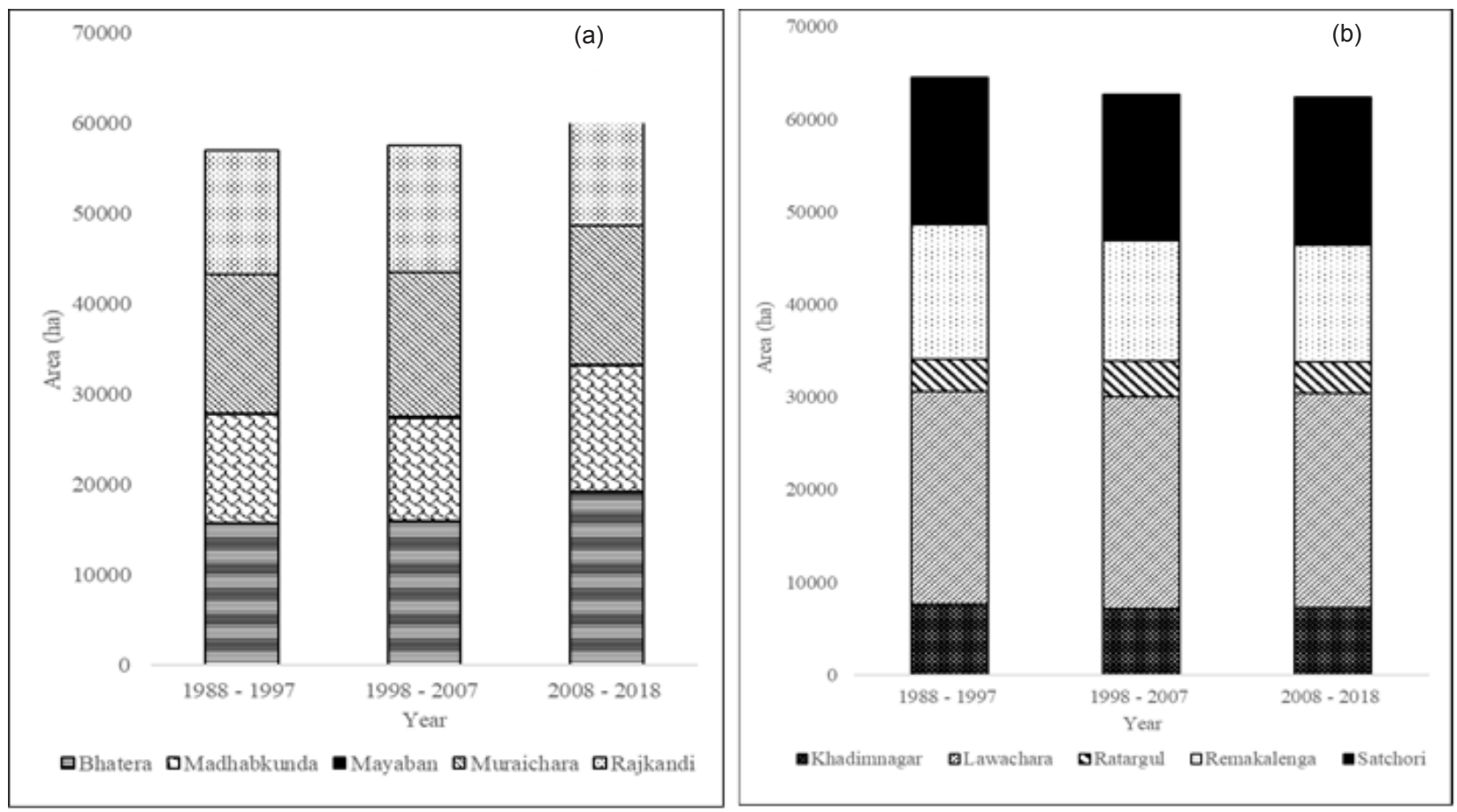

Figure 6 Comparison of forest cover area between (a) non-co-managed and (b) co-managed forest patches in Sylhet Forest Division 


\section{CONCLUSIONS}

Planning sustainable management of forests depends on a clear and objective understanding of the current status of forests. Forests in SFD are crucial to Bangladesh's efforts to achieve sustainable development goals. Yet, little or no data is available on the aggregated forest cover area in SFD. This study aimed to address the research gap by providing future projections related to changes in the areas under forest cover in SFD. Results of the study have significant policy implications as they indicated both positive and negative outcomes depending on the forest patches. Decreasing trends of areas under forest cover where co-management has been adopted indicate the need for re-evaluation of the efforts undertaken and finding reasons for the undesired changes. Also, increasing trends of forest cover in forest patches under traditional management need further evaluation so the lessons can be replicated in other forest patches of Bangladesh where traditional management has been hailed responsible for forest damages. Besides, additional studies on biodiversity, fragmentation analysis, natural regeneration studies are necessary before making any decisive remarks on the management system.

\section{ACKNOWLEDGEMENT}

This research was supported by a research grant approved and awarded by North South University Board of Trustees.

\section{REFERENCES}

Ahmed N, Islam MN, Hasan MF, Motahar T \& Sujauddin M. 2019. Understanding the political ecology of forced migration and deforestation through a multialgorithm classification approach: the case of Rohingya displacement in the southeastern border region of Bangladesh. Geology, Ecology, and Landscapes 3: 282-294. https://doi.org/10.1080/24749508.2018.1558025.

Bangladesh Forest Department. 2016. District Wise Forest Land. Bangladesh Forest Department, Dhaka. (in Bengali)

Bangladesh Forest Department. 2017. Protected Areas of Bangladesh. Bangladesh Forest Department.

Biswas SR \& Choudhury JK. 2007. Forests and forest management practices in Bangladesh: the question of sustainability. International Forestry Review 9: 627-640.

Breiman L, Friedman JH, Olshen RA \& Stone CJ. 2017. Classification and regression trees. Routledge, New York. https://doi.org/10.1201/9781315139470.
Curtis PG, Slay CM, Harris NL, Tyukavina A \& Hansen MC. 2018. Classifying drivers of global forest loss. Science 361: 1108-1111. doi: 10.1126/science.aau3445.

De Boor C. 1978. A Practical Guide to Splines. Springer-Verlag, New York. doi:10.1007/978-1-4612-6333-3.

Global Forest Watch. 2014. Tree cover in Sylhet region. www.globalforestwatch.org. (Accessed 22.10.2018)

Gorelick N, Hancher M, Dixon M, Ilyushchenko S, Thau D \& Moore R. 2017. Google Earth Engine: Planetary-scale geospatial analysis for everyone. Remote Sensing of Environment 202: 18-27. https://doi.org/10.1016/j. rse.2017.06.031.

Halim MA, Shahid A, Chowdhury MSH et al. 2008. Evaluation of land-use pattern change in West Bhanugach Reserved Forest, Bangladesh, using remote sensing and GIS techniques. Journal of Forestry Research 19: 193. https://doi.org/10.1007/s11676-008-0044-1.

Hansen MC, Potapov PV, Moore R et al. 2013. Highresolution global maps of 21 st-century forest cover change. Science 342: 850-853. doi: 10.1126/ science.1244693.

HaQue SMS. 2013. Introduction to Forestry in Bangladesh. University of Chittagong, Chittagong.

Kenney JF \& Keeping ES. 1962. Linear regression and correlation. Pp 252-285 in Mathematics of Statistics. Third edition. Van Nostrand, Princeton.

Islam KN, Rahman MM, Jashimuddin M, Hossain MM, Islam K \& FAroQue MA. 2019. Analyzing multi-temporal satellite imagery and stakeholders' perceptions to have an insight into how forest co-management is changing the protected area landscapes in Bangladesh. Forest Policy and Economics 101: 70-80. https://doi.org/10.1016/j.forpol.2019.01.011.

Lamb D, Erskine PD \& Parrotta JA. 2005. Restoration of degraded tropical forest landscapes. Science 310: 1628-1632. doi: 10.1126/science.1111773.

Mahbub RB, Ahmed N, Rahman S, Hossain MM \& Sujauddin M. 2019. Human appropriation of net primary production in Bangladesh, 1700-2100. Land Use Policy 87: 104067. https://doi.org/10.1016/j. landusepol.2019.104067.

Rahman M, Khan Masa \& Roy B. 2010. Status, distribution and diversity of invasive forest undergrowth species in the tropics: a study from northeastern Bangladesh. Journal of Forest and Environmental Science 26: 149-159.

Rana MP, Tokola T, Holm H \& Kauranne T. 2011. Airborne LiDAR based forest inventory in Bangladesh for REDD plus MRV: scope and potentiality. Pp 1-8 in SilviLaser 2011. $11^{\text {th }}$ International Conference on LiDAR Applications for Assessing Forest Ecosystems. 16-20 October 2011, Tasmania.

Reddy CS, Pasha SV, Jha CS, Diwakar PG \& Dadhwal VK. 2016. Development of national database on longterm deforestation (1930-2014) in Bangladesh. Global and Planetary Change 139: 173-182. https:/ / doi.org/10.1016/j.gloplacha.2016.02.003.

Redowan M, Akter S \& Islam N. 2014. Analysis of forest cover change at Khadimnagar National Park, Sylhet, Bangladesh, using Landsat TM and GIS data. Journal of Forestry Research 25: 393-400. https://doi. org/10.1007/s11676-014-0467-9. 